\title{
Relaciones Argentina-Brasil: cooperación con algunas discordias
}

Argentina-Brazil relations: cooperation with some discord

\section{Gisela Pereyra Doval ${ }^{*}$}

\section{RESUMEN}

El objetivo general del paper es revisar las relaciones bilaterales entre Argentina y Brasil de los últimos años. Las mismas que, históricamente, han sido consideradas tendientes al conflicto, desde la década del ochenta han virado a la cooperación hasta tener visos de amistad o parcería estratégica. Sin embargo, esta amistad no está exenta de algunos roces.

Palabras clave: Argentina-Brasil; cooperación; conflicto

\begin{abstract}
The main objective of this paper is to review the bilateral relations between Argentina and Brazil in recent years. Which have historically been considered aimed at the conflict, since the 1980's have turned to cooperation to have overtones of friendship or strategic partnership. However, this friendship is not without some friction.
\end{abstract}

Key-words: Argentina-Brazil; cooperation; conflict

Tal como sucedió con otras relaciones en el Cono Sur de América, la vinculación Argentina-Brasil estuvo caracterizada -hasta no hace mucho tiempo- por la rivalidad y la competencia, manifiesta tanto en el ámbito bilateral como americano y global. Sin embargo, la rivalidad geopolítica y estratégica ha sido lentamente reemplazada por una relación de cooperación y amistad.

En el presente, los signos tanto de cooperación como de conflicto entre ambos países se dan en las mismas esferas. Es decir, las mismas cosas que generan cooperación, también son las que generan los conflictos; en palabras de Keohane

\footnotetext{
* Doctora en Relaciones Internacionales, UNR, Rosario, Argentina.
} 
“La cooperación solo ocurre en situaciones en las que los actores perciben que sus políticas están real o potencialmente en conflicto, no en las que reina la armonía. La cooperación no debe ser considerada ausencia de conflicto, sino más bien una reacción al conflicto o al conflicto potencial. Sin el fantasma del conflicto no habría necesidad de cooperar" (KEOHANE, 1988: p. 77).

Afortunadamente, en los últimos años no ha habido grandes conflictos en las áreas política, estratégica y diplomática, sólo algunos roces que mencionaremos más adelante. De esta forma, los problemas bilaterales que los gobiernos han enfrentado fueron y son, en su mayoría, de índole económica.

Las relaciones comerciales son uno de los aspectos de mayor crecimiento en el lazo bilateral, donde a pesar de las desavenencias por las trabas impuestas por ambos estados, el avance ha sido notorio. De hecho, estas relaciones se han multiplicado desde la conformación del MERCOSUR y si bien existen desavenencias en torno a sectores como el automotriz, la línea de blanco, el azucarero, el alimenticio y el calzado, es indudable la interdependencia en materia de importaciones y exportaciones. En este sentido, la Argentina ha reclamado una balanza comercial deficitaria durante gran parte de la última década; con el agravante de que la mayoría de las exportaciones argentinas están dadas por los denominados commodities, dejando el paso libre a un Brasil mucho más industrializado ${ }^{1}$ -esta tendencia general reconoce excepciones como la del sector automotriz. Esta predisposición a la desindustrialización que se viene dando desde la década del setenta en la Argentina, se agudizó con la crisis de 2001, momento en el cual capitales brasileños compraron muchas de las tradicionales plantas argentinas y otras empresas decidieron trasladarse directamente al país carioca.

La cuestión cambiaria también tuvo y tiene un peso cada vez más relevante en las relaciones bilaterales, puesto que ambos países recurrieron a dicha estrategia como una forma de hacer más competitivas sus mercancías con un consiguiente impacto en el comercio. Ambos países sostienen tipos de cambio flotantes, pero tal como señala Sevares (2009) en el caso argentino se trata de un tipo de cambio competitivo, centrado en contribuir a la recuperación del crecimiento y la expansión de la industria, con el costo de

\footnotetext{
${ }^{1}$ Esto es a nivel referencial, dejando fuera la discusión de la reprimarización de las exportaciones brasileñas.
} 
una alta inflación. Brasil por su parte, consolidó un sistema de flotación libre, revalorizando el real y, por ende, fomentando el ingreso de capitales. Esto ha desnudado durante todo el período el déficit constante que se da entre ambos estados en la coordinación macroeconómica, más allá de los discursos presidenciales. Ahora bien, la devaluación que empezó a sufrir el real puso en alerta al gobierno argentino ya que de profundizarse dicha tendencia podría darse una merma considerable de lo que vende nuestro país en el exterior. La pérdida de competitividad bilateral y el bajo crecimiento tienen un fuerte impacto en la economía argentina ya que Brasil es el principal socio comercial. Con respecto a esto último, tanto Brasil como el resto de los llamados países emergentes se verán obligados a llevar a cabo un ajuste en sus cuentas externas, que será mayor cuanto más agudo sea su desahorro con el exterior. Esto seguramente involucrará un mayor debilitamiento de sus monedas y difícilmente pueda evitarse un ajuste por el lado de las "cantidades", dado que la reversión de los flujos de capitales demandará que las economías logren un mayor superávit de la cuenta corriente, lo que ciertamente involucrará un menor crecimiento económico.

En cuanto a las Inversiones Extranjeras Directas (IED), la década del noventa se caracterizó por la lucha por la atracción de IED, teniendo primero a la Argentina como principal destinataria en el MERCOSUR, y luego a Brasil. Esta tendencia se agudizó con la crisis de 2001 como resultado de la inseguridad para los propios capitales argentinos y una prima de riesgo que sólo comenzó a estabilizarse a mediados de la primera década del nuevo siglo con la renegociación de la deuda y la salida del default. Con el advenimiento de los gobiernos de Lula y de Néstor Kirchner, se habló de un ciclo de compatibilidad ideológica y cooperación económica en la región. Esto se vio apuntalado por la sucesión de cumbres presidenciales y la firma de documentos, tales como: el Consenso de Buenos Aires, el Consenso de Río y el Acta de Copacabana. Todo esto parecía afirmar la profundización de la llamada alianza estratégica. Sin embargo, no solo las cuestiones comerciales sino las relativas a inversiones mostraron los reveses del vínculo.

“Durante el período 2003-2008, Brasil continuó su tradicional política basada en la articulación de múltiples incentivos para la radicación de inversiones extranjeras, lo cual le permitió consolidarse como una de las economías con mayores influjos de 
capital en el mundo en desarrollo. En paralelo a ello, fomentó la proyección de sus empresas como agentes inversores en el exterior. Argentina, por su lado, reportó una política signada por la ambigüedad. Sin modificar las condiciones normativas que habían estructurado la política de liberalización hacia las inversiones extranjeras (tratados bilaterales de inversión y adscripción a los mecanismos de arbitraje para la resolución de controversias), impulsó recurrentes confrontaciones con inversores extranjeros del país. En este contexto, precipitó su merma en la participación relativa como economía receptora de inversión, perdiendo posiciones en relación con otros Estados de la región latinoamericana" (Fernández Alonso, 2010).

Por otra parte, la reciente decisión de Cristina Fernández de expropiar las acciones de la empresa de capitales españoles Repsol YPF, no generó precisamente un marco de confiabilidad para atraer inversiones, sino que continuó incrementando la fuga de capitales nacionales hacia países vecinos a pesar de los controles oficiales.

En el plano de la defensa y seguridad, es posible afirmar con Fraga (2009) que el rearme brasileño tiene como principal objetivo reforzar su condición de actor global, puesto que al compararlo con otros países BRICS, se trata de aquel con menores capacidades. Este país ha incrementado su presupuesto militar ${ }^{2}$, fundamentalmente a partir de los años 2007 y 2008 dando inicio a un proceso de rearme. Para algunos tiene la vocación de desarrollar una industria doméstica en el sector, para otros profundizar su rol de moderador en la región (FRAGA, 2009) y en su propio discurso defender espacios estratégicos como la Amazonía y recuperar el rol de las Fuerzas Armadas. En palabras de su ministro de defensa, Celso Amorim (ex canciller de Lula de Silva), Brasil tiene tres áreas que considera estratégicas: la nuclear, la espacial y la defensa cibernética. El principal objetivo de la estrategia nuclear es desarrollar un submarino de propulsión nuclear para explorar y explotar los yacimientos de pre-sal ${ }^{3}$.

\footnotetext{
2 El Instituto Internacional de Estudios para la Paz de Estocolmo (Sipri) anunció que en 2010 Sudamérica había liderado el incremento global en gasto militar en un 5.8\%, teniendo a Brasil como cabecera con un aumento de su gasto en un $9.3 \%$ con respecto a 2009 y acaparando un $80 \%$ del total del aumento mencionado. En el mismo año, Argentina experimentada todo lo contrario, es decir, uno de los gastos en defensa más bajos de su historia en relación con el PBI.

${ }^{3}$ Según el Plan Estratégico de Petrobras 2009-2013, los depósitos del pre-sal están en una gran área dentro de la llamada "provincia del pre-sal" a una profundidad entre 5 a 7 mil metros. Por este motivo, la empresa necesita una tecnología especial, además de muchas inversiones para extraer ese petróleo. Esta "provincia" involucra un área total de $112.00 \mathrm{mil} \mathrm{km} 2$, aproximadamente, entre las ciudades de Florianópolis y Victoria.
} 
La tradición de rivalidad entre Argentina y Brasil comenzó a revertirse con la firma del Acuerdo de Cooperación bilateral para el Desarrollo y la Aplicación de los Usos Pacíficos de la Energía Nuclear en 1980. A partir de la década del ochenta esta rivalidad desaparece, entre otros factores, debido al proceso de redemocratización en ambos países que se complementa con los diversos mecanismos de integración regional, especialmente, el MERCOSUR. Con respecto a los últimos gobiernos, son varios los acuerdos entre ambos países en materia de seguridad traccionados por la afinidad ideológica.

Desde una perspectiva geopolítica, el convertirse en un participante global del mercado de combustibles nucleares ayudaría a Brasil a fortalecer su liderazgo a nivel regional y global. La participación activa de Brasil en la creación de la UNASUR y su propuesta para la creación de un Consejo de Defensa Sudamericano, son dos indicadores de su intención de lograr el liderazgo regional. Además, Brasil ha demostrado un esfuerzo sostenido para ampliar su influencia fuera de la región, ya sea a través de la campaña para lograr una banca permanente en el Consejo de Seguridad de las Naciones Unidas, por su participación en los economías de rápido desarrollo, como por su intención de asociarse con países desarrollados en proyectos internacionales selectivos, tales como el ITER sobre fusión nuclear (originariamente, el consorcio internacional para el Reactor Experimental Termonuclear Internacional). Con respecto a Argentina, esto podría convertirse en un potencial conflicto ya que el liderazgo nuclear ejercido por este país en América Latina se fue perdiendo debido a las sucesivas crisis políticas y económicas.

Otra arista de esta misma temática está dada por la seguridad en la triple frontera que se trata de un tema recurrente pero que se vuelve una preocupación mayor por las presiones internacionales a partir de los ataques del 11-S. Sin bien se había conformado un Comando Tripartito en la década de noventa, esto parecía insuficiente para los Estados Unidos que lo tildó como un espacio de intercambio de estupefacientes y armas, así como un ámbito dispuesto para las actividades terroristas. El resultado posterior fue la conformación del Grupo 3+1 que incluye a Estados Unidos y permite un control compartido. 
En cuanto a los temas vinculados a lo político-diplomático, cabe decir que las relaciones bilaterales han sido buenas en forma sostenida desde el cambio de percepción generado con la vuelta a la democracia. Con mayores o menores roces, con afinidad o no entre presidentes, ambos países han hecho constantes esfuerzos diplomáticos por demostrar la centralidad en la agenda externa del vecino país. Sin embargo, la creciente asimetría, llevó a algunos analistas a decir que el rol asignado no era el mismo puesto que Brasil podía utilizar el vínculo con Argentina para extrapolar su liderazgo global, siendo que la Argentina sólo estaba preocupada por usufructuar espacios de la relación bilateral, como la comercial.

Resulta central hacer hincapié en el tradicional apoyo brasileño a la postura argentina ante la Causa Malvinas, esto ha sido visto históricamente como una prueba de los mayores puntos de contacto que de conflicto entre ambos países, a diferencia de lo sucedido con Chile. Asimismo, es indudable que Brasil fue en un aliado central en la lucha por salir de la crisis que opacó la historia argentina en el año 2001. Dice Miranda:

“justamente la crisis de 2001 puso en evidencia que el único recurso que en materia de relaciones exteriores tuvo la Argentina y del que se valió para tratar de quebrar el aislamiento internacional, fue el vínculo con los países del MERCOSUR y de América Latina" (MIRANDA, 2007:29).

Esto no quita que Brasil intentó mantenerse separada de la debacle argentina y no tomar una postura en las negociaciones que la Argentina llevó adelante con los organismos de crédito internacional. No sólo Brasil sino el MERCOSUR fue el ámbito de refugio en un momento de desinserción internacional profunda por parte de nuestro país. Sin embargo, a medida que Argentina logró encaminar su proceso de reestructuración de la deuda y reparar lentamente su balanza de pagos, hubo algunos choques notables que para algunos se manifestaron en el giro hacia Venezuela. Un giro que muchos interpretaron como ideológico, pero que otros simplemente calificaron como pragmático. Una de las formas de caracterizar la relación con Brasil y con Estados Unidos, fue la de Simonoff (2007) como un triángulo donde el obvio peligro era la doble dependencia. Afirma el autor que:

"la política exterior se halla en un marco triangular cuyos orígenes están en la restauración democrática (...) las políticas exteriores actuales se construyen con un juego de equilibrio entre las tendencias autonomistas que privilegian la región y las 
de inserción restringida con una potencia hegemónica. Ninguna de ellas es una buena política exterior" (SIMONOFF, 2007: p. 81).

Tal como mencionamos previamente, se habló de entendimiento ideológico entre Kirchner y Lula, incluso del giro a la izquierda de América Latina, sin embargo, en el año 2005 comenzó a perpetrarse un desplazamiento del vínculo con Brasil y el refugio en Venezuela. La considerada armonía del inicio encontró ciertos escollos que si bien no obstaculizaron completamente las relaciones, la tornaron ciertamente conflictiva en algunos momentos. En cuanto a las cuestiones que desestabilizaron los vínculos, la mayoría están relacionadas con el creciente liderazgo de Brasil que se profundizó en este período y se afirmó, con una Argentina que acompañó y emuló las principales iniciativas brasileñas. Por este camino se puede mencionar: el eje China - Brasil - India - Rusia, la búsqueda de un asiento permanente en el Consejo de Seguridad, el impulso a la Comunidad Sudamericana de Naciones y las diferencias ocurridas en ocasión del conflicto ecuatoriano donde Argentina abogó por una negociación multilateral en el grupo Río, en la Comunidad Sudamericana y en la OEA, mientras que Brasil actuó casi en soledad enviando a Celso Amorin como mediador, mostrando su impronta de estado pivot (Bueno, 2010).

En este período, el distanciamiento de Brasil, el acercamiento a Venezuela, el incremento del tono de Kirchner crítico al avance de Washington con el proyecto del ALCA, entre otros, contribuyeron a la visión ideologizada de las decisiones argentinas. Sin embargo, es necesario afirmar que si bien el perfil de Lula fue muy distinto al de Néstor Kirchner, la postura contra el ALCA fue conjunta y hasta motorizada por Brasil. Además, la supuesta rivalidad con los Estados Unidos se acotó solo a ciertos discursos para consumo doméstico, puesto que en materias centrales para la potencia como el terrorismo, la Argentina cumplió con la firma de documentos como la Convención Interamericana contra el terrorismo y la Convención Internacional para la Represión del Financiamiento del Terrorismo.

En cuanto a los tiempos más recientes del vínculo, es de reconocer el peso que significó para Dilma Rousseff y Cristina Fernández, el rol de sus antecesores (Lula da Silva y Néstor Kirchner); en el primer caso el presidente más popular en la historia de Brasil y en el 
segundo caso el presidente que logró sacar a la Argentina de la crisis de 2001. En el caso de Cristina se vio profundizado por la muerte del ex presidente en el año 2010 y la que algunos vaticinaron como una crisis de gobernabilidad que el kirchnerismo logró esquivar. Si bien Dilma fue la candidata propuesta por el propio Lula, se dieron algunos cambios en el rumbo de la política doméstica y externa. Uno de ellos fue la condena a regímenes como el de Irán, que no sólo la acercó aún más con los Estados Unidos, sino a la Argentina por el asunto que media con dicho país relativo a los atentados terroristas perpetrados en la Argentina en el noventa.

Los principales temas que han regido la relación bilateral reciente son: la profundización de MERCOSUR desde el punto de vista social y político; la consolidación de Unasur; el multilateralismo internacional; la reforma de las Naciones Unidas; la participación en el G20; la conclusión de la Ronda de Doha; el apoyo a la Cuestión Malvinas; la cooperación nuclear y espacial; la cooperación energética, así como en otras áreas como salud, ciencia y tecnología, educación, desarrollo social y circulación de personas, entre otros. Existen diversos mecanismos que anualmente sellan el lazo en estos temas a través de proyectos conjuntos y firma de documentos. Si bien son más los puntos que nos acercan que los que nos separan, tal como hemos venido mencionando, la Argentina continúa ante el desafío de decidir cuál será su postura ante el Brasil global, espectador incólume y ocasionalmente colaborador involuntario, o agente recuperador de protagonismo internacional con políticas autonomistas.

\section{Referencias Bibliográficas}

BOTTO, Mercedes \& TUSSIE, Diana. De la rivalidad a la cooperación: límites y desafíos de un contacto creciente. In: HOFMEISTER, W., ROJAS, Francisco \& SOLÍS, Luis Guillermo (comp.), La percepción de Brasil en el contexto internacional: perspectivas y desafíos, tomo I: América Latina. 1ํㅡ. Ed. Honrad-Adenauer-Stiftung: Rio de Janeiro, 2007.

BUENO, María del Pilar. De Estocolmo a la Haya. La desarticulación de las políticas doméstica y externa de la Argentina. 1ํㅡ. Ed. Rosario: UNR editora, 2010. 
FERNÁNDEZ ALONSO, José. Las estrategias de promoción y protección de inversiones en Argentina y Brasil tras la crisis del neoliberalismo. Ponencia presentada en Jornadas de Relaciones Internacionales, Buenos Aires, FLACSO, 2010.

FRAGA, Rosendo. El rearme brasileño. Disponible en: http://www.fesseguridadregional.org/images/stories/docs/5037-001 g.pdf; 05/12/2013.

KEOHANE, Robert. Después de la hegemonía. Cooperación y Discordia en la política económica mundial. 2ํㅡ. Eduenos Aires: Grupo Editor Latinoamericano, 1988.

MIRANDA, Roberto. Brasil, Venezuela y la inserción argentina en Sudamérica. In: Autores Varios, El presente internacional de Argentina: cuestiones de su agenda de política exterior. 1ํㅡ. Ed. Río Cuarto: Facultad de Ciencias Humanas, Universidad Nacional de Río Cuarto, 2007.

SEVARES, Julio. Argentina y Brasil: diferente macroeconomía, pero la misma vulnerabilidad. Nueva Sociedad, № 219, enero-febrero, 2009.

SIMONOFF, Alejandro. La política exterior argentina reciente, con especial énfasis en la relación con Brasil y Estados Unidos. In: Autores Varios, Transitando los inicios del siglo XXI. Las relaciones de Argentina, Chile y México, 1ํㅡ. Ed. Buenos Aires: Grupo Editor Latinoamericano, 2007.

Stockholm International Peace Research Institute. SIPRI 2010 Yearbook. Armaments, disarmament and international security. Disponible en www.sipri.org; 01/04/2014. 